\title{
A Contribuição do Orientador Educacional para Professores e Alunos
}

\author{
Ricardo Santos David ${ }^{1}$ \\ ${ }^{1}$ Mestrado em Educação - UNEATLANTICO, Universidad Europea del Atlántico. Professor de língua inglesa e língua portu- \\ guesa. Universidade Candido Mendes - Rio de Janeiro
}

Recebido em 20 de maio de 2017; Aceito em 8 de junho de 2017.

\begin{abstract}
Resumo
Entender a orientação educacional quando esta surge e como esta se configura hoje é de suma importância para entender a importância da mesma no desenvolvimento humano e social. $\mathrm{O}$ trabalho pedagógico necessário à sociedade democrática não é o de implementação passiva de diretrizes educacionais e a consequente preparação dos alunos para apenas executarem ordens. A escola tem o direito e o dever de organizar o trabalho pedagógico que continua para formação do cidadão. $O$ direito se refere ao respeito pelo trabalho dos profissionais da educação, sobretudo, o supervisor pedagógico, que nela atuam, assim como o direito do aluno de ter uma educação que necessita como pessoa. Portanto, a necessidade de construção coletiva do projeto político pedagógico implica que todos participem também da sua avaliação em todos os momentos e dimensões do trabalho. O projeto pedagógico é a própria organização do trabalho pedagógico da escola, construída e reconstruída continuamente pela equipe escolar, executado e avaliado por todos os que atuam na escola. Por ser a avaliação da aprendizagem uma comprovação e qualificação de um projeto, se faz necessário que saiba distinguir as mesmas de acordo com sua finalidade. Assim, o objetivo deste estudo é demonstrar a gênese da orientação educacional, demonstrando sua importância na sociedade até os dias atuais. Para isso a metodologia utilizada foi à revisão crítica de literatura em educação e orientação educacional.
\end{abstract}

Palavras-chave: Gestão pedagógica; orientação educacional; educação; supervisão escolar.

\begin{abstract}
Understand the educational guidance when it arises and how it is configured today is of paramount importance to understand the importance of it in the human and social development. The pedagogical work necessary for democratic society is not the passive implementation of educational policies and the consequent preparation of students to only execute orders. The school has the right and the duty to organize the educational work that continues to form the citizen. The right refers to respect for the work of education professionals, especially the educational supervisor, who in her work, as well as the right of students to have an education you need as a person. Hence the need for collective construction of the political pedagogical project implies that all participate also the review at all times and dimensions of work. The educational project is the very organization of school educational work, continuously built and rebuilt by the school team, run and evaluated by all who work in the school. Being the evaluation of learning a demonstration and qualification of a project, it is necessary to know to distinguish them according to their purpose. The objective of this study is to demonstrate the genesis of educational guidance, demonstrating its importance in society to the present day. To that the methodology used was to critically review the literature in education and educational guidance.
\end{abstract}

Keywords: Educational management; educational guidance; education; school supervision. 


\section{INTRODUÇÃO}

Percebe-se que a Educação deve ser plena, portanto deve romper a dicotomia informar e educar. A promoção dessas práticas e de sua apreciação crítica deve levar em consideração a vida cotidiana dos alunos, dos professores, da realidade local e dos valores que ali estão presentes, enfim, a cultura de seu próprio grupo.

Nesse mesmo sentido, delega-se autonomia para uma proposta pedagógica integrada de Educação, na qual o planejamento deve estar inserido, atribuindo responsabilidade à escola e aos seus professores pela elaboração e implementação da ação educativa adequada às diferentes realidades e demandas sociais. É revestido dessa autonomia que todo supervisor pedagógico, deve ter em mente a necessidade de dominar os assuntos pedagógicos referentes a sua instituição de ensino; conhecer os alunos, sua escola e sua comunidade; desenvolver uma proposta pedagógica adequada e que tenha significado para seu próprio grupo.

O profissional da prática docente, além de um conjunto de conhecimentos técnicos provindos de sua formação acadêmica, lida com um conjunto de valores, hábitos, com uma tradição, com um determinado contexto, enfim, atualizam significados continuamente.

Possui uma história de vida, que o fez escolher a prática pedagógica em detrimento de outras carreiras profissionais; possui um jeito de dar aulas; relaciona se com professores de outros componentes curriculares; lida com uma expectativa que sobre ele é colocada pela direção da escola e pela coordenação pedagógica; lida cotidianamente com os alunos e suas motivações e interesses; é influenciado pela mídia.

Possui, enfim, um imaginário social que orienta e dá sentido aquilo que faz. É neste sentido que se pode considerar a cultura escolar como um processo dinâmico, repleto de sutilezas e representações sociais. Não considerar esses aspectos da Educação é correr o risco de se perder, ou numa discussão reducionista de competência técnica, ou num idealismo teórico e dogmático. Essa discussão sugere também que a ansiada transformação da prática, desejada por todos considerarem o nível das representações sociais ancorado nas ações dos profissionais de educação.

O projeto pedagógico ou proposta pedagógica de cada escola deve ser construído coletivamente, num processo que busque o comprometimento dos profissionais da educação com os valores e objetivos traçados, de forma que os articule com a realidade local da comunidade escolar. Numa discussão metodológica se faz necessário uma exposição epistemológica.

Esta, por sua vez, deverá tornar explícitas as raízes teóricas que a definem, como se entende no método o processo de conhecer, ou seja, as relações que unem e opõem ao mesmo tempo um sujeito que conhece e um objeto que se conhece. A teoria geral do conhecimento, sendo uma expressão conceitual das leis objetivas que regem o conhecimento, implica, sem confundir-se com elas, as leis do pensamento, isto é, a lógica.

Também se deve incluir uma conceituação ou teoria do objeto sobre o qual o método se aplicará, sobretudo, em referência àqueles aspectos próprios e específicos do objeto que condicionam a elaboração dos passos metodológicos e das técnicas ou instrumentos do método. Isto acontece pelo fato de que não se pode aplicar a determinados objetos técnicas que são próprias de objetos de outra natureza, sem correr o risco de violentar-Ihes a natureza. Por fim, todo método deve expor a seqüência lógica dos passos a seguir para alcançar o objetivo predeterminado, e as distintas técnicas utilizadas, a fim de mostrar como ambos traduzem, a nível operacional, tanto os fundamentos epistemológicos, como os aspectos específicos do objeto sobre o qual se pretende atuar. 
A metodologia deste estudo está centrada na pesquisa e coleta de informações de ordem teórica viabilizada, portanto, através de levantamento bibliográfico. Segundo o autor Severino (2006, p.130), o trabalho metodológico está sendo concluído com a realização de estudo por meio de pesquisa bibliográfica referentes ao tema enfocado. Portanto, a pesquisa bibliográfica será elaborada por meio da consulta a diversos títulos de autores variados, procurando assim um melhor embasamento teórico para a pesquisa. Buscando ideias e linhas de pensamento diversificadas, para o enriquecimento e melhoria do embasamento da pesquisa.

\section{GESTÃO ESCOLAR}

O objetivo deste capítulo é resgatar historicamente as definições sobre a gestão e a supervisão escolar. Desse modo, pretendemos apresentar como surgiu e se desenvolveu a gestão escolar, que é, tecnicamente, um conceito novo dentro da administração escolar e da supervisão escolar que não somente deve estar voltado para a delatoria, mas que nasceu da mesma.

O termo gestão, como aludido no texto introdutório, é uma expressão recente, que vem ganhando notoriedade dentro do contexto educacional, como resultado da mudança de paradigmas que vem acompanhando o setor educacional.

Uma escola que atenda as atuais exigências sociais, no sentido de formação de cidadãos e ainda oferecer a possibilidade de aprendizagem de competências e habilidades facilitadoras da inserção social, necessita de uma Gestão Escolar moderna que caminhe lado a lado com o contexto sócio-cultural da atualidade. Essa gestão divide-se em três outras classificações ou três áreas, sistematicamente interligadas: Gestão Pedagógica; Gestão de Recursos Humanos e Gestão Administrativa.

A Gestão Pedagógica é considerada como o lado mais importante da Gestão Escolar, no momento em que sua função é gerir toda a área educativa, não só da escola, mas também da educação escolar. A mesma é responsável por traçar e estabelecer os objetivos do ensino, tanto gerais quanto específicos. Do mesmo modo, define as linhas de atuação de acordo com as metas e o perfil dos alunos e da comunidade circundante à escola.

O ponto de partida do referido tipo de gestão é a elaboração da proposta das metas, seguida dos conteúdos escolares. Da mesma forma que traça os objetivos e define as linhas de atuação, acompanha e avalia o rendimento das propostas pedagógicas, dos objetivos e do cumprimento de metas, trabalhando também na avaliação dos alunos, do corpo docente e da equipe escolar. Todas as especificidades da Gestão Pedagógica estão enunciadas no Regimento Escolar e no Projeto Pedagógico. O Diretor de Escola é o articular da Gestão Pedagógica, auxiliado pelo Coordenador Pedagógico, caso haja.

A função da Gestão Administrativa é cuidar da parte física e institucional da escola. Pela parte física, a Gestão Administrativa responde pelo prédio e pelos equipamentos, não somente das aquisições, mas também de sua manutenção. Pela fatia institucional, a Gestão Administrativa cuida da legislação escolar, direitos e deveres, e as atividades de secretaria Suas especificidades também estão enunciadas no Plano Escolar.

Com o mesmo nível de importância que as demais gestões, a Gestão de Recursos Humanos representa a parte mais sensível de toda a Gestão Escolar. Sem dúvida, lidar com pessoas e seus problemas, contorná-los e ainda tirar o maior rendimento profissional possível dos indivíduos é tarefa das mais difíceis.

Por fim, a organização destas três gestões, corresponde a uma formulação teórica em nível de discurso, pois as três se fundem em apenas uma, na medida em que trabalham de forma integrada, com vistas a garantir a organização do processo educativo. 
De acordo com Machado (2007), em seu início a supervisão escolar foi praticada no Brasil em condições que produziam o ofuscamento e não a elaboração da vontade do supervisor. O objetivo pretendido com a supervisão que se introduzia, era o de uma educação controlada, para uma sociedade controlada, um supervisor controlador e também controlado.

Nas palavras de Lück (2005), existem profissionais eficazes, no entanto se limitam às orientações da diretoria e/ou de diretores que seguem à risca a legislação, e não interferem nos processos sociais da escola que está sob sua responsabilidade.

Educação não é um processo episódico ou de modismo. Educação é um processo longo e continuado que segue as linhas do tempo, adequando-se ao contexto em que ele está inserido naquele momento. Educação não pode sofrer remendos ou paliativos para superar eventuais dificuldades cotidianas.

O ser humano, tanto os alunos, quanto os professores estão em constante mutação. Entretanto, por mais que estes seres mudem seus conceitos e suas atitudes, ainda assim são seres que possuem necessidades comuns, como a necessidade de sentirem-se motivados, e motivação implica em responsabilidades e necessidade do novo. Portanto, cada ato deverá ser dirigido a metas que devam ser alcançadas a curto, médio ou longo prazo, mas precisam de alguma forma chegar ao objetivo. Segundo Klink, citado por Lück (2005), "Pense grande e aja no pequeno". Ou seja, avalie todos os pequenos detalhes que possam colaborar com o sucesso ou o insucesso do empreendimento.

De acordo com Machado (2007),

O supervisor hoje deve trabalhar de forma coletiva, com todos da unidade escolar (Professores, Direção etc.), para que se possa fazer uma análise consciente sobre o cotidiano escolar e do cotidiano da sociedade, atendendo as necessidades e aspirações da comunidade escolar, para uma melhor qualidade de ensino (MACHADO, 2007, p. 33).

Devemos sempre ter em mente que tanto o aspecto administrativo quanto pedagógico irá de manifestar de maneira dupla no sistema escolar brasileiro. De acordo com o autor acima citado, as duas práticas acabam por não se distinguir de forma substancial.

De um lado, a administração institucionalizada prepondera sobre a preocupação e a própria realização do ensino nas salas de aula, de outro a administração como objeto de estudo não chega a sofrer a investigação e a análise que possibilitariam a revisão crítica de seu significado (MACHADO, 2007, p. 37).

Desse modo, podemos dizer que supervisionar uma dada escola é orientar sua administração para a realização do ensino, sendo este de qualidade e que atenda na medida do possível as demandas que tanto a sociedade coloca sobre a escola quanto os próprios alunos assim as façam. Neste sentido, podemos perceber que o que dará sentido ao trabalho de supervisionar em educação é o suporte ao trabalho pedagógico. $O$ trabalho pedagógico como um determinante do trabalho administrativo. Segundo Machado (2007), "o que nos falta, para organizar melhor a confluência de nossa subjetividade é considerar que o aspecto administrativo é também um componente do trabalho pedagógico".

Nesta perspectiva podemos perceber como a supervisão dentro da gestão escolar é passível de adaptações promovendo não somente um melhor fluxo administrativo, mas também nas relações existentes dentro da comunidade escolar.

Machado (2007), ainda conclui que a supervisão, de hoje, 
Poderá contribuir decisivamente para o reconhecimento de seu papel de articulador do projeto pedagógico de uma coletividade, ou seja, O Supervisor trabalhando em conjunto com todos da comunidade escolar refletindo, analisando, tendo uma visão crítica tanto da comunidade escolar, como da sociedade, buscando a elaboração de uma nova visão de mundo, sendo solidário, reconhecendo o indivíduo com a síntese de múltiplas determinações ajudando a construir a vontade coletiva que transforma a necessidade em liberdade, com certeza teremos um ensino de boa qualidade (MACHADO, 2007, p. 42).

Assim, podemos considerar que a partir do momento em que a gestão escolar passa a ser considerada por viés democrático, tendo na supervisão escolar algo que seja de extrema cooperação dentro da comunidade escolar, teremos, enfim, uma participação emancipadora.

Esse tipo de participação se dará a partir do momento em que as pessoas envolvidas no processo educacional, ou seja, toda a comunidade escolar entenda a importância de sua participação e acompanhamento não somente do processo de ensino e aprendizagem do seu filho, mas de como a escola atua na comunidade, fará com que esta se torne cada vez mais consciente de suas responsabilidades e direitos, conscientes que as mudanças sociais somente virão a partir do momento em que os mesmos participem ativamente na construção e manutenção das instituições sociais.

\section{SUPERVISOR ESCOLAR}

Nesse mesmo sentido, delega-se autonomia para uma proposta pedagógica integrada de Educação, na qual o planejamento deve estar inserido, atribuindo responsabilidade à escola e aos seus professores pela elaboração e implementação da ação educativa adequada às diferentes realidades e demandas sociais.

É revestido dessa autonomia que todo supervisor pedagógico, deve ter em mente a necessidade de dominar os assuntos pedagógicos referentes a sua instituição de ensino; conhecer os alunos, sua escola e sua comunidade; desenvolver uma proposta pedagógica adequada e que tenha significado para seu próprio grupo.

Conforme Chauí (1986, p. 21), a ideologia é o ocultamento da realidade social, portanto, "por seu intermédio, os homens legitimam as condições sociais de exploração e dominação, fazendo com que pareçam verdadeiras e justas". Desvelar essas ideias ou representações que procuram explicar e compreender a vida, individual, social do profissional e sua relação de dominação política e de exploração econômica é função da escola através do compromisso dos autores do Projeto Político Pedagógico, orientado pelo supervisor de ensino.

Então, quando me refiro ao papel do supervisor, não é simplesmente para enumerar um rol de atividades diárias, conforme já explicitei anteriormente a questão da nomenclatura. Parto do pressuposto de que a reflexão contínua fará com 25 que o supervisor esteja sempre buscando novos caminhos, novas respostas, com o objetivo de dinamizar sua ação na escola.

Analisando o papel desenvolvido pelo supervisor de ensino, ao longo do tempo, percebemos que ele hoje é muito diferente do exercido em tempos anteriores, mas, em algumas situações, ainda persiste a fiscalização e a prática burocrática.

Para Silva Junior (1997, p. 102), "é preciso reconhecer inicialmente a prisão burocrática no interior da 
qual o supervisor se movimenta".

Quando o supervisor não tem clareza da dimensão maior no que se refere às políticas educacionais e no âmbito escolar, ele passa a reproduzir as normas advindas do sistema sem questionar. Para questionar, concordar ou discordar de algo é necessário primeiro conhecer. Infelizmente, na maioria das vezes, os supervisores não sabem explicar suas ações firmadas em um contexto mais amplo.

Acredito que para mudar é preciso conhecer. O supervisor só consegue uma mudança, tanto no seu papel na categoria profissional, quanto no seu espaço de trabalho, quando é capaz de conhecer o contexto mais amplo no qual se insere a escola como instituição social. Somam-se a estes os aspectos políticos que determinam as ações da escola e reproduzem as teorias pedagógicas.

Na ausência de uma finalidade educativa, o supervisor desenvolve as funções burocráticas e as normas emanadas da mantenedora, sem comprometimento com o social, ou, até mesmo, com o seu grupo de trabalho, na sua escola. Passa a exercer a antiga função de controle entendido por Fernandes (1997, p. 120) como aspecto característico do papel da supervisão, exercido sempre em benefício do poder vigente, e não da educação.

Nesse sentido, as leis estabelecem os objetivos do sistema escolar. A função de controle da supervisão é legitimada na legislação educacional, e reflete, na sua organização, uma concepção de mundo, homem, sociedade e conhecimento, inerentes a uma determinada política que rege a sociedade em cada época. Ou seja, o sistema educacional tende a reproduzir dentro de si as condições e contradições dessa sociedade.

Uma das contradições do supervisor tem sido, concretamente, responder à organização burocrática do sistema. Há duas possíveis explicações para essa prática: a primeira é que as práticas administrativas e fiscalizadoras estão embutidas no próprio processo histórico desse profissional; a segunda é a falta de reflexão sobre sua própria prática, sobre o cotidiano de suas ações, em vista de uma finalidade educativa. Essa carga burocrática presente na função de supervisor acaba apresentando-se como um problema, a ser combatido pelo próprio supervisor, evitando que a obediência cega, a falta de espírito crítico e a acomodação passiva Ihe impeçam de perceber a necessidade da realização de sua função.

\section{O PAPEL DO COORDENADOR PEDAGÓGICO NA FORMAÇÃO CONTINUADA DOS PROFESSO- RES}

Muitos dos problemas enfrentados atualmente no exercício da coordenação pedagógica têm sua origem na configuração formal da função, associada ao controle. A introdução da supervisão educacional traz para o interior da escola a divisão social do trabalho, ou seja, a divisão entre os que pensam, decidem, mandam, e os que executam; até então, o professor era o ator e autor de suas aulas, a partir disto passa a ser expropriado de seu saber, colocando-se entre ele e o seu trabalho a figura do técnico. Em função dessa origem profissional ligada ao poder e controle autoritários, há necessidade de o coordenador assumir uma postura diferenciada e conquistar a confiança dos educadores.

A atuação da coordenação pedagógica se dá no campo da mediação, pois quem está diretamente vinculado a tarefa de ensino, é o professor. O supervisor relaciona-se com o professor visando sua relação diferenciada, qualificada com os alunos. Neste contexto, é preciso atentar para a necessária articulação entre a pedagogia da sala de aula e a pedagogia institucional, uma vez que, o que está em questão é a mesma tarefa: a formação humana, ou seja, a formação dos alunos, dos professores, da coordenação e dos pais.

O coordenador, ao mesmo tempo em que acolhe e engendra, deve ser questionador, desequilibrador, 
provocador, animador e disponibilizando subsídios que permitam o crescimento do grupo, tem um papel relevante na formação dos educadores, ajudando a elevar o nível de consciência: tomada de consciência. Freire (2007), passagem do senso comum à consciência filosófica. Saviane (2003), ou a criação de um novo patamar para o senso comum. Santos (2008). Passar de uma supervisão para outra - visão.

Fusari, (2008) defende que o trabalho ativo e intencional do coordenador, sempre articulado com o projeto político pedagógico da escola, favorece ao professor a tomada de consciência sobre a sua ação e sobre o contexto em que trabalha, bem como, pode-se afirmar, que favorece o próprio repensar do coordenador sobre a sua atuação. O professor, como também o coordenador, consciente de sua prática, das teorias que embasam e das teorias que cria e desenvolve ao resolver problemas diários, é um profissional inserido no processo de formação contínua, em busca de mudanças e fundamentações criteriosas para a sua prática.

Essa tarefa formadora, articuladora e transformadora é difícil, primeiro, porque não há fórmulas prontas a serem reproduzidas. É preciso criar soluções adequadas a cada realidade. Segundo, porque mudar práticas pedagógicas não se resume a uma tarefa técnica de implementação de novos modelos a substituir programas, métodos de ensino e formas de avaliação costumeiras. Mudar práticas significa reconhecer limites e deficiências no próprio trabalho, significa lançar olhares questionadores e de estranhamento para práticas que nos são tão familiares que pareçam verdadeiras, evidentes ou impossíveis de serem modificadas.

Significa alterar valores e hábitos que caracterizam de tal modo nossas ações e atitudes que constituem parte importante de nossa identidade pessoal e profissional. Mudar práticas implica o enfrentamento inevitável e delicado de conflitos entre os participantes, originados de visões de mundo, valores, expectativas e interesses diferentes. Mudar práticas pedagógicas significa empreender mudanças em toda cultura organizacional. (GARRIDO, 2008).

Não há como falar de formação de professores sem levar em conta a formação inicial, cujo papel é fornecer as bases para a construção de um pensamento pedagógico especializado. Parece ser consenso entre os estudiosos do assunto que a formação inicial representa o começo da socialização profissional e a inserção nos âmbitos cultural, contextual, científico e pessoal que vão permear a prática pedagógica. Assim, espera-se que a formação inicial fomente processos reflexivos sobre a teoria e a realidade social em que os futuros professores irão atuar. (SANTOS, 2008).

Portanto, é preciso pensar a formação docente como momentos de um processo contínuo de construção de uma prática docente qualificada e de afirmação da identidade do professor. Visto que, a formação continuada deve ser centrada na escola, Conforme Canário, (1998 apud ALMEIDA, 2006) a escola é o lugar onde os professores aprendem. É o lugar onde os saberes e as experiências são trocadas, validadas, apropriadas e rejeitadas. Pensar em formação de professores implica repensar modelos e atitudes com relação a esse profissional.

\section{CONCLUSÃO}

Conforme visto neste estudo a educação é algo essencialmente humano desenvolvido por e para ele, de forma que deve atender à sua emancipação, fazendo com que o homem entenda e transforma sua realidade conforme necessário. Ao longo do tempo, no entanto, a educação vai sendo formatada de acordo com as demandas sociais de cada época, ou seja, a educação vira uma ferramenta de formação humana sendo que esta formação irá variar conforme as necessidades da sociedade vigente.

A educação, então, desenvolve paradigmas, ou seja, modelos e valores que variam conforme a época e são esses que moldas as práticas pedagógicas dos professores, bem como selecionam os conteúdos que 
devem ser passados aos alunos bem como ele deve ser passado, tendo em vista o plano maior do desenvolvimento social e econômico.

Dessa forma, tudo o que cerne à educação toma forma aos paradigmas vigentes e, como não deveria, a orientação educacional não foge desta premissa demonstrando que esta funcionará, ou melhor, terá seus objetivos e funções formatadas conforme as demandas sociais e os paradigmas educacionais de cada época.

Observou-se, porém, que atualmente a educação pública brasileira passa por inúmeros problemas de diversas ordens e entre eles estão: fala de recursos, políticas educacionais ineficazes e quando são eficazes sofrem com a corrupção e desvio de recursos, má remuneração dos professores, má formação dos mesmos que acarreta na má qualidade de ensino.

Desse modo, a orientação educacional acaba por sair daquela utopia de objetivos educacionais para virar uma ferramenta de solução de problemas que nem sempre cabe à escola resolver e, dessa forma, essa função vai sendo deixada de lado pela sobrecarga que gera em cima do orientador.

\section{REFERÊNCIAS}

ALMEIDA, L. R. A dimensão relacional no processo de formação docente. In: BRUNO, E. B. G. ALMEIDA, L. R (orgs.) O Coordenador Pedagógico e a Formação Docente. 7 Ed. São Paulo: Edicões Loyola, 26.

BRASIL, Ministério da Educação e Cultura. Parâmetros Curriculares Nacionais. Ensino Fundamental Ministério da Educação e Cultura. Brasil: Brasília, 17.

BRASIL. Lei $n$ - .3 4 6. Estabelece as Diretrizes e Bases da Educação Nacional.

CHAUÍ, M. Conformismo e resistência. São Paulo, Brasiliense, 16.

FREIRE, P. Supervisão educacional: uma reflexão crítica. 13. Ed. Petrópolis: Vozes, 27

FERNANDES, M. M. A opção da supervisão diante da ambivalência. In: SILVA Jr, C. A. RANGEL, M. (orgs.). Nove olhares sobre a supervisão. Campinas: Papirus, 1 7. p.111-121

FUSARI, J. C. Formação contínua de educadores na escola e em outras situações. In: BRUNO, E. B. G., ALMEIDA, L.R., CHRISTOV, L.H.S. (orgs.) O coordenador Pedagógico e a Formação Docente. Ed. São Paulo: Ediç es Loyola, 2 .

GARRIDO, E.. Espaço de Formação Continuada para o Professor-Coordenador. In: BRUNO, E. B. G., ALMEIDA, L.R., CHRISTOV, L.H.S. (orgs.) O coordenador pedagógico e a formação docente. Ed. São Paulo: Ediç es Loyola, 2 .

MACHADO, A. Supervisão Escolar: novos desafios e propostas (2 7)

SAVIANI, D. A supervisão educacional em perspectiva histórica: da função à profissão pela mediação da ideia. In: FERREIRA, S. C. N. (Org.). Supervisão educacional para uma escola de qualidade. 4. Ed. São Paulo: Cortez, 2 3. P.13-3.

SANTOS, A.R.. LDB .3 4 6: Alguns Passos na Formação de Professores no Brasil. In: GRANVILLE, M.A.. (org.) Teorias e Práticas na Formação de Professores. 2 Ed. Campinas, SP: Papi- rus, 2 .

11 Revista Ciências Humanas - UNITAU, Taubaté SP - Brasil, v. 1 , n 1, edição 1 , p. 1 - 117, Junho 2 17A Contribuição do Orientador Educacional para Professores e Alunos

SEVERINO, A.J. A busca do sentido da formação humana: tarefa da Filosofia da Educação. Educ. Pes- quisa. 2 6, v. 32, n. 3.

SILVA JUNIOR, C. A.da. Organização do trabalho na escola pública o pedagógico e o administrativo na ação supervisora. In: JUNIOR, C. A. da S. e RANGEL, M. (orgs). Nove olhares sobre a supervisão. Campinas, SP: Papirus, 1 7, p. 1-1 . 